Etnográfica

Revista do Centro em Rede de Investigação em

Antropologia

vol. 22 (2) | 2018

Vol. $22(2)$

\title{
Práticas artísticas e espaço urbano: renovando compromissos com a observação etnográfica
}

Artistic practices and urban space: renewing commitments to ethnographic observation

Pedro Costa

\section{(2) OpenEdition}

Journals

Edição electrónica

URL: https://journals.openedition.org/etnografica/5395

DOI: 10.4000/etnografica.5395

ISSN: 2182-2891

Editora

Centro em Rede de Investigação em Antropologia

Edição impressa

Data de publição: 1 junho 2018

Paginação: 389-394

ISSN: 0873-6561

Refêrencia eletrónica

Pedro Costa, «Práticas artísticas e espaço urbano: renovando compromissos com a observação etnográfica», Etnográfica [Online], vol. 22 (2) | 2018, posto online no dia 07 julho 2018, consultado o 19 janeiro 2022. URL: http://journals.openedition.org/etnografica/5395 ; DOI: https://doi.org/10.4000/ etnografica. 5395

\section{(c) (i) (8)}

Etnográfica is licensed under a Creative Commons Attribution-NonCommercial 4.0 International License. 


\section{Práticas artísticas e espaço urbano: renovando compromissos com a observação etnográfica}

\section{Pedro Costa}

O dossiê que propomos procura explorar novos caminhos quanto aos contributos da pesquisa etnográfica para o conhecimento das relações entre práticas artísticas e espaço urbano. Assumindo um compromisso renovado com uma observação etnográfica intimamente relacionada com os territórios e as comunidades que são o seu alvo de pesquisa, mobilizam-se os artistas e as práticas artísticas como objetos ativos do processo de investigação sobre os territórios urbanos, explorando novas práticas heurísticas e questionando o primado do investigador sobre o seu objeto de pesquisa. Os contributos reunidos exploram formas distintas de fazer esta aproximação, todas elas apostadas em esbater as fronteiras entre as práticas artísticas e as etnográficas: seja pela utilização da intervenção artística como objeto ativo de questionamento e de reflexividade das próprias comunidades; seja pela utilização da deambulação e da observação etnográfica urbana como formas de cartografar e entender as práticas artísticas; ou seja ainda pela mobilização da pesquisa etnográfica para apurar de modo detalhado e aprofundado as vivências e práticas dos protagonistas artísticos urbanos e a sua relação com os territórios.

PALAVRAS-CHAVE: urbano, práticas artísticas, intervenções urbanas, cocriação de conhecimento, território, pesquisa etnográfica.

Artistic practices and urban space: renewing commitments to ethnographic observation - The dossier seeks to explore new paths about the contributions of ethnographic research to the knowledge of the relationship between artistic practices and urban space. Assuming a renewed commitment with a kind of ethnographic observation which is intimately engaged with the territories and communities that are the target of its research, the artists and artistic practices are mobilized as objects with an active role in the research processes about urban territories, exploring new heuristics and questioning the primacy of the investigator upon his research object. The contributions gathered explore different ways to do this approach, all of the three wagered in blurring the boundaries between artistic and ethnographic practices: using the artistic intervention as an active object of questioning and of reflexivity for the communities; using urban wandering and urban ethnographic observation as forms of mapping and understanding the artistic practices; and mobilizing ethnographic research as a way to establish in a detailed and thorough mode the experiences and practices of urban artistic protagonists and their relationship with the territories.

KEYWORDS: urban, artistic practices, urban interventions, knowledge co-creation, territory, ethnographic research.

COSTA, Pedro (pedro.costa@iscte-iul.pt) - ISCTE - Instituto Universitário de Lisboa, Dinâmia'CET-IUL, Portugal. 
A RELAÇÃO ENTRE PRÁTICAS ARTÍSTICAS E ESPAÇO URBANO TEM SIDO proficuamente explorada, nos últimos anos, no questionamento dos mecanismos de transformação, (re)produção e revitalização das cidades contemporâneas, intimamente associados aos processos de globalização e de reestruturação socioeconómica dos territórios contemporâneos. Por outro lado, a relação entre práticas artísticas e espaço urbano tem sido ela própria igualmente muito mobilizada no problematizar das lógicas fortemente territorializadas que enraízam a criação e a fruição cultural. As dinâmicas de liminaridade e de transgressão associadas à criação artística; as lógicas de construção e gestão das reputações dos diversos intervenientes dos processos criativos e artísticos (do autor ao gatekeeper ou ao "consumidor"/“espetador" cultural, mais ou menos "emancipado"...); as transformações dos estilos de vida e a forma como a estetização do quotidiano e a performatividade em espaço público têm interferido nos processos e nas dinâmicas culturais; ou ainda as formas como a esfera simbólica tem sido marcante na evolução do "lugar" (das construções identitárias às dinâmicas de gentrificação e turistificação) - todos estes são aspetos que têm vindo a fazer ressaltar esta relação na contemporaneidade, e para os quais muitas das próprias práticas artísticas recentes em espaço urbano têm vindo a contribuir crescentemente.

$\mathrm{Na}$ esfera do capitalismo cognitivo-cultural atual (Scott 2008, 2014) a construção, acumulação e descodificação do conhecimento, e nomeadamente do conhecimento simbólico e estético, faz-se através de um conjunto de processos nos quais as atividades artísticas e culturais desempenham uma centralidade indiscutível e onde, portanto, as suas "ferramentas" tradicionais serão uma "vantagem competitiva" importante. Os mecanismos de mediação cultural, cada vez mais diversificados, abrem-se como campo privilegiado de afirmação de um conjunto de novas (ou, pelo menos, mais abrangentemente legitimadas...) práticas artísticas e como espaço de experimentação de novas lógicas de intermediação e de (re)construção de reputações e legitimações. Num quadro urbano marcado por múltiplas camadas de negociação e transformação, aos mais diversos níveis, das condicionantes morfológicas às lógicas de informalidade, das dinâmicas de conflito aos arranjos de governança, por exemplo (veja-se o caso dos meios criativos, por exemplo, em Costa e Lopes 2013, 2015), esta questão torna-se particularmente importante, colocando os artistas e criadores num novo e (re)valorizado papel na construção de cada "lugar" e das dinâmicas territorializadas que lhe estão subjacentes ( $c f$. Traquino 2010; Scott 2014).

Da mesma forma, esta relação entre prática artística e espaço urbano apresenta um potencial ainda claramente subexplorado na interface, também ela fulcral, entre práticas artísticas e pesquisa científica. As novas práticas e lógicas heurísticas associadas à utilização de metodologias participativas (visuais ou outras) ou a assunção de uma investigação etnográfica mais virada para o 
estudo feito "com" as comunidades do que "sobre" ou "para" as comunidades têm dado passos significativos neste sentido, que importa agora entender e aprofundar. É este compromisso renovado com uma observação etnográfica intimamente comprometida com os territórios e as comunidades que são o alvo de pesquisa que queremos trazer para a discussão neste dossiê temático. Assumindo os artistas e as práticas artísticas como objeto deste estudo de base etnográfica, mas também mobilizando-os como objetos ativos do processo de investigação (seja explorando novas práticas heurísticas, seja questionando o primado do investigador sobre o seu objeto de pesquisa), procuramos explorar novos caminhos quanto aos contributos da pesquisa etnográfica para o conhecimento das práticas artísticas em espaço urbano.

Os três contributos que aqui se reúnem permitem indicar três formas distintas de fazer esta aproximação, todos eles no caminho de esbater as fronteiras entre as práticas artísticas e as práticas etnográficas: seja pela via da utilização da intervenção artística como objeto ativo de questionamento e de reflexividade das próprias comunidades, seja pelo caminho da utilização da deambulação e da observação etnográfica urbana como formas de cartografar e entender as práticas artísticas, ou seja ainda pela via da mobilização da pesquisa etnográfica como forma de apurar de forma detalhada e aprofundada as vivências e práticas dos protagonistas artísticos urbanos e a sua relação com os territórios.

No primeiro artigo, intitulado "Dos dois lados do espelho: diálogos com um bairro cultural através da intervenção urbana", Pedro Costa e Ricardo Lopes assumem-se como observadores-participantes e como promotores-instigadores de um conjunto de intervenções artísticas num contexto urbano específico que têm vindo a estudar há muito, o Bairro Alto. Neste texto, os autores apresentam um conjunto de três intervenções urbanas que desenvolveram neste bairro lisboeta, em três anos consecutivos, em articulação com um programa de pesquisa sobre dinâmicas criativas em bairros culturais de diversas cidades, intervenções essas que lhes permitiram desenvolver novas heurísticas para a sua pesquisa e aprofundar a reflexão sobre o potencial da intervenção artística na relação com a comunidade e o conhecimento do território. Estas experiências exploraram abordagens participativas baseadas em diferentes disciplinas artísticas (fotografia, instalação, artes performativas, intervenção urbana), permitindo testar um conjunto de ideias em relação às lógicas de apropriação do espaço, às dinâmicas de liminaridade e de conflito nele existentes, e à capacidade de vitalização urbana, que se podem associar à intervenção artística em espaços das cidades. Os autores partem do princípio de que as intervenções artísticas em bairros culturais podem ser uma boa forma de compreender as múltiplas camadas de usos, codificações e segregações que afetam estes espaços urbanos e que contribuem para a sua vitalidade quotidiana, assumindo-as como um elemento valioso para ampliar a gama de recursos problematizadores 
que temos disponíveis para apreender as cidades na sua complexidade. Defendem assim que estas intervenções artísticas permitem complementar e testar na prática muitos dos resultados obtidos pelos processos de investigação mais "convencionais" utilizados na pesquisa sobre esses espaços urbanos, permitindo um diálogo a diferentes níveis com as comunidades locais e deslocando o foco das ferramentas conceptuais e analíticas do investigador para o próprio objeto de estudo. É neste quadro que tentam extrair alguns princípios para enriquecer o debate entre processos de pesquisa científica e intervenção artística urbana.

No segundo artigo, "Arte como política de resistência: dispositivos cartográficos na apreensão de práticas culturais juvenis em uma cidade do Nordeste do Brasil", Denise Laranjeira, Mirela Figueiredo Iriart e Eduardo Luedy descrevem o seu processo de pesquisa-ação e a importância de uma observação participante baseada numa etnografia urbana de inspiração cartográfica, que pretende compreender o papel da arte nos processos de inserção social e política dos jovens em Feira de Santana, na Baía, no Nordeste do Brasil. A produção e difusão cultural de alguns coletivos e circuitos culturais juvenis desta cidade são apreendidos a partir de um conjunto de itinerários que acompanham as "deambulações pela cidade" de alguns jovens e as suas redes de sociabilidade, permitindo desvendar as suas dimensões formativas, estéticas, éticas e políticas. A metodologia desenvolvida permite alcançar e descrever aspetos menos previsíveis e algumas singularidades, "pequenas coisas" que menos diretamente se apreendem, mas que são reveladoras de uma cultura que está muito para lá das marcas mais institucionalizadas, à margem da cultura hegemónica. Acompanhando grupos de músicos hip-hop, dançarinos, graffiters, poetas, e um conjunto de eventos potenciadores de sociabilidades entre jovens que ultrapassam as suas múltiplas diferenças (culturais, étnicas, raciais ou de género), os autores deambulam com os jovens pela cidade, por espaços afetivos por eles próprios selecionados, observando, entrevistando, registando fotograficamente, participando. A par do potenciar de redes que favoreçam o empoderamento e o acesso à cidadania efetiva aos jovens que são o objeto deste estudo, o principal objetivo dos autores, neste processo de pesquisa-intervenção, centra-se, mais do que no delimitar de territórios e suas formas de fruição, no traçar das "rotas e redes" onde os sujeitos se reinventam nas tensões e contradições do espaço urbano e como pensam e produzem a sua relação com a cidade, os seus desejos e projeções.

Finalmente, no terceiro e último artigo, intitulado "Arte colaborativa: uma observação localizada dos teatros e dos seus públicos", Vera Borges apoia-se na observação minuciosa das práticas artísticas, centrando-se na ideia de uma "arte feita em conjunto", uma "arte com todos" que tem por base a observação do trabalho de três estruturas artísticas portuguesas: a Alma d'Arame, a d'Orfeu e o Teatro Viriato. Baseando-se numa "microetnografia de interações" 
dos teatros e dos seus protagonistas na sua relação com os territórios e as populações envolventes, a autora procura mergulhar nas formas como estas estruturas culturais produzem e (re)constroem no quotidiano a sua relação com a comunidade, para além das retóricas que muitas vezes marcam mais os discursos do que as práticas. Extrair os sentidos daquilo que é localmente relevante para estas pessoas é um dos seus objetivos, interpretando as missões de cada comunidade num compromisso com a observação e a prática etnográficas. Esta prática é reveladora da diversidade de rotinas, mas também de ruturas dos quotidianos de trabalho artístico, das práticas, interações e representações colaborativas de grupos locais. A autora defende que as estruturas que apelam à participação da população configuram contextos de forte convivialidade com os seus públicos, podendo aumentar o bem-estar e qualidade de vida de um "pequeno círculo" de habitantes locais. Conjugando a análise das vocações, missões e objetivos particulares dos indivíduos, mas também dos grupos, territórios e parceiros locais e dos seus públicos-participantes e intervenientes, a autora utiliza a observação etnográfica dos grupos e seus protagonistas, dos seus contextos artísticos e das suas trajetórias territoriais, para procurar chegar aos públicos que cada estrutura vai mobilizando e envolvendo, o que, segundo as suas conclusões, se traduz numa "ampliação" da definição de cultura que estas estruturas estão dispostas a proporcionar às comunidades envolventes.

No seu conjunto, estes três artigos permitem-nos equacionar, de forma bastante diversa, (re)nova(da)s formas de repensar a investigação sobre as relações entre as práticas artísticas e o espaço urbano. As múltiplas possibilidades abertas pelo enunciar exploratório destas três vias metodológicas, mas também, decerto, através de muitos outros caminhos alternativos, permitem-nos procurar formas menos convencionais de ultrapassar alguns dos frequentes bloqueios à análise dos espaços urbanos contemporâneos, evidenciando as "subjetividades negociadas" presentes em muitos dos "dilemas do quotidiano" que dão corpo às tensões entre socialização e individualização que caracterizam as sociedades atuais, caracterizadas por múltiplas e complexas modulações identitárias, em íntima relação com diferentes formas de reflexividade (Pais 2010). Pelo seu caráter liminar e muitas vezes disruptor, mas também pelo potencial heurístico que o seu caráter intensivo em conhecimento estético e simbólico desempenha nestes tempos do capitalismo cognitivo-cultural contemporâneo, potenciando novas formas de diálogo e novos mecanismos de produção de conhecimento, as práticas artísticas serão decerto um "instrumento" poderoso para trabalhar com as comunidades no melhor entendimento dos seus territórios, cocriando conhecimento e abrindo vias que nos permitem renovar e solidificar os compromissos com uma observação etnográfica dos espaços urbanos, que permita esbater as difusas, e não raras vezes artificiais e indesejáveis, fronteiras entre a produção artística e a produção científica. 


\section{BIBLIOGRAFIA}

COSTA, Pedro, e Ricardo LOPES, 2013, “Urban design, public space and creative milieus: an international comparative approach to informal dynamics in cultural districts”, Cidades, Comunidades e Territórios, 26: 40-66.

COSTA, Pedro, e Ricardo LOPES, 2015, "Urban design, public space and the dynamics of creative milieux: a photographic approach to Bairro Alto (Lisbon), Gràcia (Barcelona) and Vila Madalena (São Paulo)", Journal of Urban Design, 20 (1): 28-51.

PAIS, José Machado, 2010, Lufa-Lufa Quotidiana: Ensaios sobre a Cidade, Cultura e Vida Urbana. Lisboa, Imprensa de Ciências Sociais.

SCOTT, Allen J., 2008, Social Economy of the Metropolis: Cognitive-Cultural Capitalism and the Global Resurgence of Cities. Oxford, Oxford University Press.

SCOTT, Allen J., 2014, "Beyond the creative city: cognitive-cultural capitalism and the new urbanism”, Regional Studies, 48 (4): 565-578.

TRAQUinO, Marta, 2010, A Construção do Lugar pela Arte Contemporânea. Ribeirão, Húmus. 